\title{
National-Scale Forest Soil Carbon Characterizing Using Reflectance Spectroscopy
}

\author{
Asa Gholizadeh ${ }^{\mathrm{a}, *}$, Raphael A. Viscarra Rossel ${ }^{\mathrm{b}}$, Mohammadmehdi \\ Saberioon $^{c}$, Josef Kratina ${ }^{a}$, Lubos Boruvka ${ }^{a}$, Lenka Pavlu ${ }^{a}$ \\ ${ }^{a}$ Department of Soil Science and Soil Protection, Faculty of Agrobiology, Food and \\ Natural Resources, Czech University of Life Sciences Prague, Kamycka 129, Suchdol, \\ Prague 16500, Czech Republic \\ ${ }^{b}$ Soil and Landscape Science, School of Molecular and Life Sciences, Faculty of Science \\ and Engineering, Bentley Campus, Curtin University, G.P.O. Box U1987, Perth WA \\ 6845, Australia \\ ${ }^{c}$ Helmholtz Centre Potsdam GFZ German Research Centre for Geosciences, Section 1.4 \\ Remote Sensing and Geoinformatics, Telegrafenberg, Potsdam 14473, Germany
}

\section{Abstract}

Any strategy to change the Carbon (C) pool has a substantial effect on the functionality of numerous ecosystem functions, the detachment of Soil Organic Carbon (SOC), the atmospheric carbon dioxide $\left(\mathrm{CO}_{2}\right)$ concentration, and climate change mitigation. As the largest amount of the world's $\mathrm{C}$ is stored in forests soils, the importance of forest SOC management is highlighted. The total SOC in a forest varies not only laterally, but also vertically (i.e., with depth). However, the SOC storage of different forest soil horizons has not been investigated in a national scale thoroughly, despite their potential to frame our understanding of soil function. Visible-Near Infrared (vis-NIR) reflectance spectroscopy enables rapid examination of the horizontal distribution of forest SOC, overcoming the limitations of traditional soil assessment methods. This study aims to evaluate the potential of

*Corresponding author;Email address: gholizadeh@af.czu.cz (Asa Gholizadeh) 
vis-NIR spectroscopy in characterizing and predicting the SOC content of organic and mineral horizons in forests. We investigate 1080 forested sites across the Czech Republic at five individual soil layers, representing the Litter $(\mathrm{L})$, Fragmented (F), and Humus $(\mathrm{H})$ organic horizons, as well as the $A_{1}$ (depth of 2-10 cm) and $A_{2}$ (depth of 10-40 cm) mineral horizons (for a total of 5400 samples). We, then, use Support Vector Machines (SVMs) to classify the soil horizons based on their spectra and also to predict the SOC content of (i) the profile (all organic and mineral horizons together), (ii) the combined organic horizons, (iii) the combined mineral horizons, and (iv) each individual horizon separately. The models are validated using 10-repeated 10-fold cross validation. The results show that there is at least more than seven times as much SOC in the combined organic horizons, compared to the combined mineral horizons, with more variation in the deeper layers. The SVM with radial based kernel is a reliable classifier for classification of soil horizons, with Correct Classification Rate (CCR) of 70\% and Kappa coefficient of 0.63. All individual horizon SOCs are successfully predicted with low error and with $\mathrm{R}^{2}$ values higher than 0.63 . However, the prediction accuracies of the $\mathrm{F}$ and $\mathrm{A}_{1}$ models are greater, compared to others $\left(\mathrm{R}^{2}>0.70\right.$ and very low-biased spatial estimates). We conclude that the modelling of SOC with vis-NIR spectra in different soil horizons of highly heterogeneous forests in the Czech Republic is practical. This study provides an example of how general pedological knowledge can be used to define depth functions of SOC for forested sites.

Keywords: Soil organic carbon, Climate change, Forest soil, Soil horizons, National scale, Reflectance spectroscopy 


\section{Introduction}

Concerns regarding Carbon (C) loading of the atmosphere from soil have significantly increased scientific interest in soil, as it is the largest terrestrial pool for long-term C storage (Batjes, 1996; Deluca \& Boisvenue, 2012). In particular, the potentially major effects of soil $\mathrm{C}$ on the atmospheric carbon dioxide $\left(\mathrm{CO}_{2}\right)$ concentration (Schlesinger, 1995), as well as its ability to sequester Soil Organic Carbon (SOC) and mitigate climate change (Cienciala et al., 2008; Viscarra Rossel et al., 2019) has attracted the attention of environmental research and policy agendas. Soil contains more C than the atmosphere (Bellassen \& Luyssaert, 2014; Lal, 2017; Zdruli et al., 2017) and is the main component of the $\mathrm{C}$ cycle on Earth. Thus, SOC is crucial to preserving soil quality and health, assuring food security, and mitigating climate change (Lal, 2004, 2016). Climate change causes an increased biomass production as well as $\mathrm{CO}_{2}$ concentrations and, as a result, causes an unbalanced C cycle (England \& Viscarra Rossel, 2018). In this context, SOC management must be a part of an international plan to understand the $\mathrm{SOC}$ pools and the role of soil in the global $\mathrm{C}$ cycle.

Forest soil has high SOC content, well-developed organic horizons, excessive spatial variability, and features discernible variations in SOC with depth (IPCC, 2000). The SOC amount in forest soil is a function of the alteration between the $\mathrm{C}$ in surface litter and the below-ground biomass, as well as root exudates to the soil profile. It decreases due to decomposition, erosion, and leaching (Black et al., 2014). SOC in a forest ecosystem is stored in different horizons (Lal, 2008; Brahma et al., 2018) with different concentrations, due to the different stages of decomposition (Gibson et al., 2002). Accordingly, 
evidence has been presented which suggests that measurements should extend to different horizons (Wendt \& Hauser, 2013; Lorenz \& Lal, 2014; Fan et al., 2016). Since the Climate Summit (COP21) in Paris in December 2015, there has been much interest in the storage of SOC in the top $40 \mathrm{~cm}$ of soil (Lal, 2017), which has been categorized into organic and mineral horizons by Zanella et al. (2017).

The spatial variability of forest SOC content is scale-dependent (Goidts et al., 2009; Hutengs et al., 2019). Small-scale variation of SOC occurs due to site-specific topography, erosion, drainage, different lithology and weathering intensities, biological activity, temporal effects of soil moisture, and soil management (Ellert et al., 2001; Conen et al., 2004; Saby \& Arrouays, 2004; Kirwan et al., 2005; Yoo et al., 2006; Vanguelova et al., 2016). Largescale SOC variability is related to topography and land use (Jian-Bing et al., 2006; Smith, 2008; Griffiths \& Madritch, 2009; Webster et al., 2011; Barcena et al., 2014; Fernandez-Romero et al., 2014). At regional or national scales, it is necessary to evaluate the impact of the number of observations and associated soil variability on SOC content detection (Saby \& Arrouays, 2004; Bellamy et al., 2005; Chamberlain et al., 2010). However, the characterization and prediction of SOC in organic and mineral horizons of forests at a national scale with conventional analytical methods is laborious and costly, as a large number of samples are needed in such a large heterogeneous soil $\mathrm{C}$ pool (Palmer et al., 2002; Conen et al., 2004; Vanguelova et al., 2016), particularly for depth measurements (England \& Viscarra Rossel, 2018). Thus, it is crucial to measure and monitor SOC in forest soil effectively and with sufficient accuracy using reliable, quick, and low-cost techniques not only 
vertically, but also horizontally.

Visible-Near Infrared (vis-NIR) spectrometers allow many more measurements to be made across the landscape at depth and in time, such that the data can sufficiently characterize the spatial (vertical and lateral) and temporal variability of soil (Viscarra Rossel et al., 2017). Reflectance spectroscopy can also provide rapid, inexpensive, accurate, and non-destructive measurements of SOC content and composition at different scales (Ben-Dor \& Banin, 1995; Stenberg et al., 2010; Knadel et al., 2012; Viscarra Rossel \& Hicks, 2015; Gholizadeh et al., 2018; Liu et al., 2019). There have been a few local-scale studies which investigated the use of reflectance spectroscopy for assessing forest SOC in different horizons (Jiang et al., 2017; Wang et al., 2019; Zhao et al., 2019), although the spectroscopic models established by these studies usually need to be recalibrated repetitively across different research locations, which limits the capability of vis-NIR spectroscopy extremely. Characterizing and developing large-scale (e.g., at a national or global scale) SOC models may provide an approach for improving the effectiveness of the technique (Viscarra Rossel et al., 2016); however, we did not find any published literature on the application of vis-NIR spectroscopy for classifying and predicting forest SOC in different soil horizons at a national scale.

To this end, we intend to test whether vis-NIR spectroscopy can be used to characterize and determine forest soils in the Czech Republic for the purpose of more informed management of forest soils. Our hypothesis is that vis-NIR spectroscopy can help us to better understand the composition of SOC in forest soils and to accurately and cost-effectively classify and pre- 
dict SOC concentrations. Thus, our aims were (i) to characterize forest soils using only the information content of the spectra, (ii) to predict the SOC content of the forest soil profile, combined organic, and combined mineral horizons, as well as individual horizons, using the spectra, and (iii) to assess the prediction ability of the models.

\section{Materials and Methods}

\subsection{Study Sites, Soil Sampling, and Measurements}

The Czech Republic has a total land area of $78,865 \mathrm{~km}^{2}$, of which $34 \%$ is covered by forest (Czech Statistical Office, 2019) (Figure 1).

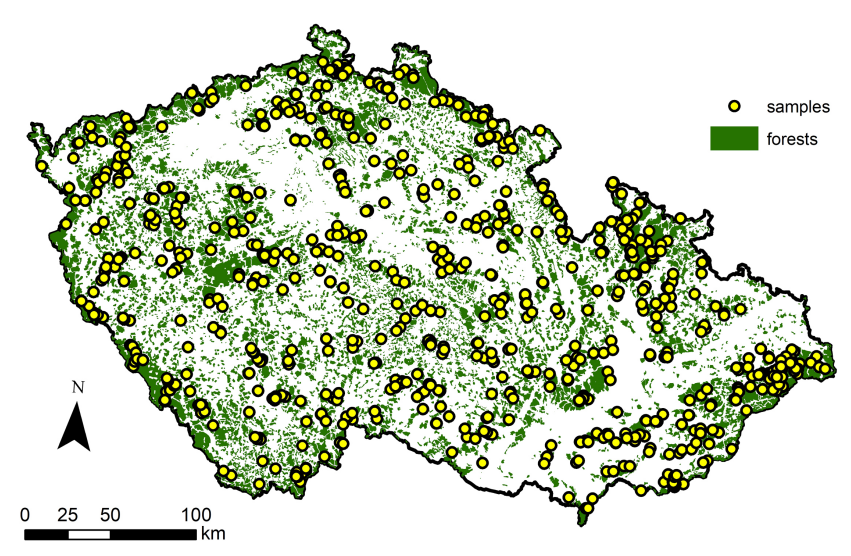

Figure 1: Location of Czech forests and soil sampling sites.

The soil sampling sites in this study were distributed over all the forested areas of the country, in order to proportionally represent various forest stands (e.g., forest composition, soil classes, and altitudes). The proportions of various tree species, soil classes, and altitudes are shown in Table 1. Sites with 
prevailing coniferous trees formed about two thirds of the total set of sampling locations (65.6\%), Norway spruce (Picea abies L. Krast.) being the most frequent species (51.5\%), followed by Scots pine (Pinus sylvestris L., 13.8\%). Among sites with prevailing broad-leaved trees (34.4\%), oak (Quercus sp., 17.9\%) and European beech (Fagus sulvatica L., 16.6\%) dominated. Cambisols were the dominant soil class (70.1\%), mainly Dystric (36.7\%), Hyperdystric (28.9\%), and Eutric (22.6\%). Podzols (15.4\%) and Stagnosols (5.2\%) were also quite abundant; the other soil classes (e.g., Arenosols, Leptosols, Retisols, Luvisols, and Fluvisols) were less frequent. The largest proportion of sampling sites were located between $400 \mathrm{~m}$ and $600 \mathrm{~m}$ a.s.l. (47.1\%). With increasing and decreasing altitudes from this range, the number of sites was decreased. This corresponds to relative proportion of various altitudes in the Czech Republic and the distribution of forests.

The samples originated from the Forest Soil Survey (Fiala et al., 2013) from the years 2000-2008 and were collected from 1080 points in forested sites across the whole Czech Republic (Figure 1). At each site, soil samples were collected separately from five individual layers (for a total of 5400 samples); namely, organic horizons Litter (L), Fragmented (F), and Humus (H), as well as mineral horizon A (with thickness ranging usually from 2-10 cm) $\left(A_{1}\right)$ and subsurface mineral horizon (usually to the depth of $40 \mathrm{~cm})\left(\mathrm{A}_{2}\right)$. At each sampling site, composite soil samples were created from several subsamples collected in a circle of $10 \mathrm{~m}$ in diameter.

The soil samples were air-dried, ground, sieved $(\leq 2 \mathrm{~mm})$, and thoroughly mixed before the soil analyses. SOC was determined using the rapid dichromate oxidation technique (Sparks, 1996). 


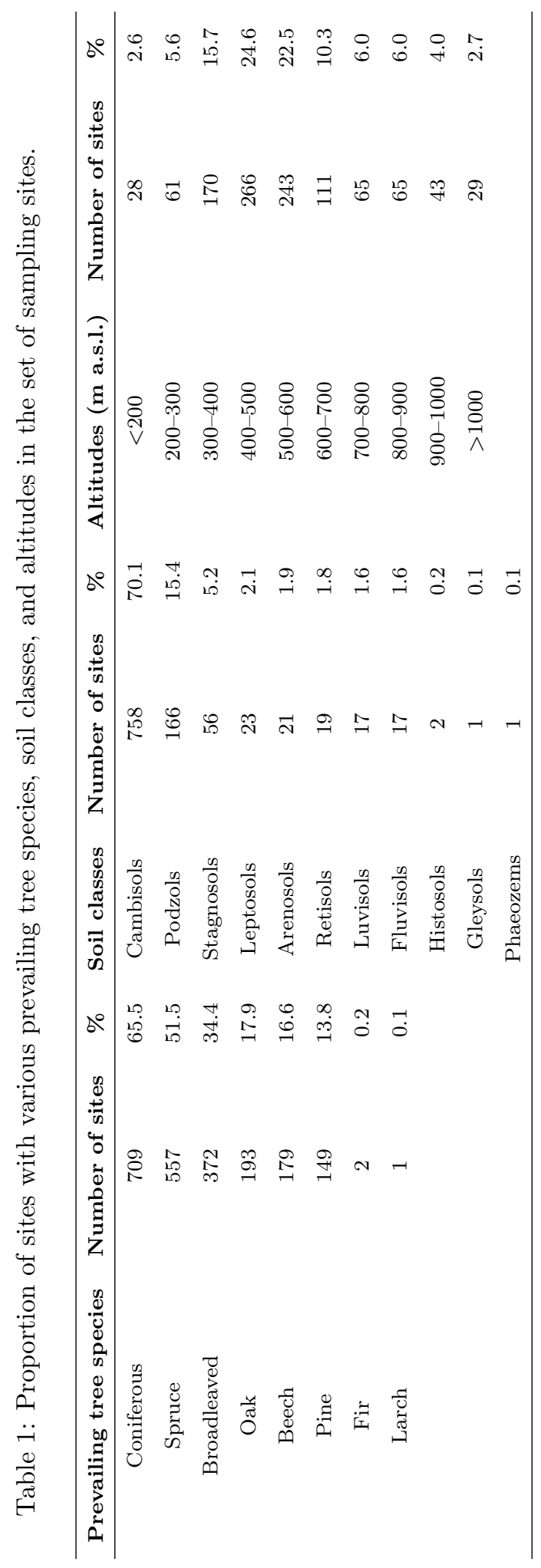




\subsection{Organic and Mineral Horizons}

The study was designed to test variation in SOC as a function of soil horizon. Organic and mineral horizons representatives of various SOC contents were selected for the current study. Based on the World Reference Base for Soil Resources (IUSS Working Group WRB, 2015), the main criteria for distinguishing between organic and mineral horizons is $\mathrm{C}$ content, which is higher than $20 \%$ for the organic horizons. According to Zanella et al. (2017), as coloured by organic matter, organic horizons (L, F, and H) are generally darker ( $\mathrm{H}$ is almost black) in colour than the lower mineral horizons of the soil profile (divided into the individual horizons $\mathrm{A}_{1}$ and $\mathrm{A}_{2}$ ), which depend on animal and fungal activities, as well as the effects of soil forming processes.

\subsection{Spectroscopic Measurements and Preprocessing}

Spectroscopic measurements were made in the range of 350-2500 nm using an ASD FieldSpec Pro FR spectroradiometer (ASD Inc., Denver, Colorado, USA) with a high intensity contact probe. The spectral resolution of the spectroradiometer was $2 \mathrm{~nm}$ for the region of $350-1050 \mathrm{~nm}$ and $10 \mathrm{~nm}$ for the region of 1050-2500 nm. Moreover, the radiometer bandwidth from 350$1000 \mathrm{~nm}$ was $1.4 \mathrm{~nm}$, while it was $2 \mathrm{~nm}$ from $1000-2500 \mathrm{~nm}$. The instrument ran for about 30 minutes, in order to allow the spectrometer and lamp to warm. Soil samples were placed in $9 \mathrm{~cm}$ diameter petri dishes, forming $2 \mathrm{~cm}$ layers of soil. This was done to avoid beam reflectance from the bottom of the dish, due to down-welling solar and sky radiation penetrating into the soil at approximately $1 / 2$ the wavelength (Jensen, 2007), which could have an unwanted effect (i.e., modifying the soil spectra). Samples were levelled off using a stainless steel blade to guarantee a flat surface (flush with the top of 
the petri dish), as a smooth soil surface ensures maximum light reflection and a high Signal-to-Noise Ratio (SNR) (Mouazen et al., 2005). We measured all spectral readings in the center of the samples (with 3 replicates each) in a dark room to avoid interference from stray light. The spectroradiometer was optimized using a white Spectralon ${ }^{T M}$ (Lab-sphere, North Sutton, New Hampshire, USA) prior to the first scan and after every six measurements (Shi et al., 2016). For each soil measurement, 30 spectra were averaged to improve the SNR.

Before proceeding with our analysis, the spectral reflectance (R) was transformed into apparent absorbance spectra through $\log _{10}(1 / R)$ and then preprocessed using Savitzky-Golay smoothing with a second-order polynomial fit, a window size of 10 wavelengths, and first derivatives (Savitzky \& Golay, 1964). Due to the high collinearity of the spectra, we retained only every tenth wavelength from $350 \mathrm{~nm}$ to $2500 \mathrm{~nm}$ inclusive to reduce dimensionality (Viscarra Rossel \& Webster, 2012). Principal Component Analysis (PCA) and the scores of Principal Components (PCs) were performed. Scatterplots of these components were used to visualize the structure of the data and to emphasize the SOC variations in different horizons (Viscarra Rossel et al., 2016; Dotto et al., 2018), as SOC contents seemed clearly distinct at various depths. It was also a requirement to analytically identify reference data outliers in the data sets (Martens \& Naes, 1992). We checked the histograms of data and tested for outliers, both visually and using the Cook distance, which has been used in regression analysis to find influential outliers in a set of predictor variables (Cook, 1977; Kim, 2017). Wavelet decomposition was performed to keep only those coefficients that would be 
useful in the models. For this purpose, we followed the methodology presented in Viscarra Rossel \& Lark (2009), which involves the selection of the wavelet coefficients based on their variance, regardless of wavelet scale. The selected coefficients were then used as the predictors. The resulting spectra from Continuum Removal (CR) technique (Clark \& Roush, 1984) were used to assist in the spectral interpretation in the database.

\subsection{Spectroscopic Modelling and Assessment Statistics}

To train and then validate our models, the data was randomly split into a training set $(75 \%)$ and a testing set $(25 \%)$. The training set was used to build the classification and regression models and the test set was used to verify the generalization ability of the developed models (Kooistra et al., 2003). For the spectroscopic classification and prediction, we used the Support Vector Machine (SVM) algorithm, which is a supervised, non-parametric, and kernelbased learning method from statistical learning theory (Vapnik, 1998). It has been identified to strike the correct balance between the accuracy gained from a given limited amount of training patterns and the generalization capability to handle unseen data. Viscarra Rossel \& Behrens (2010) and Gholizadeh et al. (2016) have described the implementation of SVM for spectroscopic modelling in detail. All of the spectroscopic models were validated using 10repeated 10-fold cross validation (Hastie et al., 2009; Viscarra Rossel et al., $2017,2019)$ and the validation statistics reported are the means of the 10 repeats. Non-parametric bootstraps were used to quantify the uncertainty of the SVM models in SOC estimation, in which we sampled with replacement from the training data (Hastie et al., 2009; Viscarra Rossel, 2007); this means that the method used the raw data to generate new data sets (Hastie et al., 
2009).

The potential of the SVM classification was evaluated through the analysis of Correct Classification Rate (CCR) and Cohens Kappa coefficient in the validation set (Saberioon et al., 2018). Moreover, we assessed the performance of the prediction models by comparing the predicted values on the independent test data set with the observed ones using standard model evaluation statistics; the coefficient of determination $\left(R^{2}\right)$ between the observed and predicted values of SOC, the Root Mean Squared Error (RMSE), and the Mean Error (ME) or bias (Viscarra Rossel et al., 2006). $\mathrm{R}^{2}$ is defined as the proportion of variation in the response that can be explained by the regression model. RMSE is the parameter commonly used in vis-NIR spectroscopy literature to describe the prediction ability of a model. The bias or ME appears as the error of means and is independent (Bellon-Maurel et al., 2010; Gomez et al., 2016). Table 2 shows the statistical metrics for models evaluation.

Table 2: Statistical metrics to evaluate SVM calibration.

\begin{tabular}{lc}
\hline Statistics & Formula \\
\hline Correct Classification Rate (CCR) & $\frac{N_{1}}{N_{0}} \times 100 \%$ \\
Kappa coefficient & $\frac{\operatorname{Pr}(a)-\operatorname{Pr}(e)}{1-\operatorname{Pr}(e)}$ \\
Coefficient of determination (R $\left.{ }^{2}\right)$ & $1-\frac{\sum_{i=1}^{N}\left(\hat{y}_{i}-y_{i}\right)^{2}}{\sum_{i=1}^{N}\left(y_{i}-\overline{y_{i}}\right)^{2}}$ \\
Root Mean Squared Error (RMSE) & $\sqrt{\frac{\sum_{i=1}^{N}\left(\hat{y}_{i}-y_{i}\right)^{2}}{N}}$ \\
Mean Error (ME) or bias & $\frac{1}{N} \sum_{i=1}^{N}\left(\hat{y}_{i}-y_{i}\right)$ \\
\hline
\end{tabular}

The resulting spectroscopic models yielded from SVM was used to classify 
soil horizons and predict the SOC content of the forested areas, at different organic and mineral horizons, where we measured spectra. Thus, we made a total of 5400 estimates at 1080 sites.

\section{Results}

\subsection{Descriptive Statistics of SOC at Different Horizons}

Table 3 summarizes the statistics of the estimated SOC, including Mean, Minimum (Min), Maximum (Max), Standard Deviation (SD), Coefficient of Variation (CV), and skewness for data from all sampling locations for the profile, combined organic and combined mineral horizons, and the individual layers. There was a large variation in SOC content in the forest soil profile, as well as between all individual horizons, which reflects the different depths from which the samples originated (Viscarra Rossel \& Behrens, 2010). The whole profile results indicate that the average SOC content of all samples was $23.54 \% \pm 17.12 \%$ (SD), with a distribution that shows high variability $(\mathrm{CV}=73 \%)$ and an approximate normal distribution (skewness $=-0.06)$.

Table 3: Statistical summary of SOC (\%) for each horizon.

\begin{tabular}{lcccccccc}
\hline Soil horizon & Samples n. & Mean & Median & Min & Max & SD & CV & Skewness \\
\hline Profile & 5400 & 23.54 & 27.03 & 0.18 & 52.71 & 17.12 & 73 & -0.06 \\
Combined organic horizons & 3240 & 36.12 & 39.00 & 3.85 & 52.71 & 9.18 & 25 & -1.06 \\
Combined mineral horizons & 2160 & 4.62 & 4.11 & 0.18 & 25.20 & 3.26 & 70 & 1.59 \\
L & 1080 & 42.91 & 43.57 & 25.90 & 52.71 & 3.50 & 8 & -0.50 \\
$\mathrm{~F}$ & 1080 & 38.67 & 39.35 & 4.25 & 48.79 & 6.02 & 16 & -1.83 \\
$\mathrm{H}$ & 1080 & 26.79 & 27.83 & 3.85 & 45.98 & 8.05 & 30 & -0.49 \\
$\mathrm{~A}_{1}$ & 1080 & 6.49 & 6.22 & 0.82 & 25.20 & 3.20 & 49 & 1.56 \\
$\mathrm{~A}_{2}$ & 1080 & 2.74 & 2.33 & 0.18 & 23.75 & 1.99 & 73 & 2.99 \\
\hline
\end{tabular}


The average SOC content in the $\mathrm{L}$ horizon was high (mean $=42.91 \%$ ); it varied from $25.90 \%$ to $52.71 \%$. In the horizons $\mathrm{F}$ and $\mathrm{H}$, the SOC contents were lower $($ mean $=38.67 \%$ and $26.79 \%$ ), with ranges of $4.25-48.79 \%$ and $3.85-45.98 \%$, respectively. The $\mathrm{SOC}$ content in the $\mathrm{A}_{1}$ horizon ranged from $0.82 \%$ to $25.20 \%$, with an average value of $6.49 \%$; while the $\mathrm{A}_{2}$ horizon showed an average SOC content of $2.47 \%$ and minimum and maximum of $0.18 \%$ and $23.75 \%$, respectively. On average, there was at least more than seven times as much SOC (concentration) in the combined organic horizons (mean $=36.12 \%)$, compared to the combined mineral horizons $($ mean $=4.62 \%)$. The data distribution characteristic was found using the value of the SD. For instance, the $\mathrm{SD}$ values of the $\mathrm{SOC}$ in the top organic sets $(\mathrm{L}, \mathrm{F}$, and $\mathrm{H})$ were $3.50 \%, 6.02 \%$, and $8.05 \%$, respectively, and were thus higher than those of the lower mineral sets $\mathrm{A}_{1}$ and $\mathrm{A}_{2}$ (3.20\% and $1.99 \%$, respectively). The SOC data for all horizons had skewed distributions. The individual organic horizons ( $\mathrm{L}, \mathrm{F}$, and $\mathrm{H}$ ) statistical distributions were negatively skewed, where horizon F had a strongly skewed distribution (with a skewness of $<-1$ ), while L and $\mathrm{H}$ were mildly skewed. The distribution of SOC in the individual mineral horizons $A_{1}$ and $A_{2}$ was more skewed than those of the organic horizons and they were strongly positive, with higher means than medians. In this study, a comparison of layer CVs showed that, among all horizons, $\mathrm{A}_{2}$, as a mineral horizon, had the highest CV (73\%). In contrast, the organic horizon L had the lowest CV (8\%), which shows that its distribution was more homogeneous than other individual horizons, partly caused by its (highest) mean. 


\section{2. vis-NIR Spectral Data at Different Horizons}

The continuum-removed spectra with their SDs for the soil samples from organic and mineral horizons are shown in Figure 2, which illustrates some minor spectral changes in the shape of the spectra and more apparent differences in the depth of absorption bands from the upper to the lower horizons.
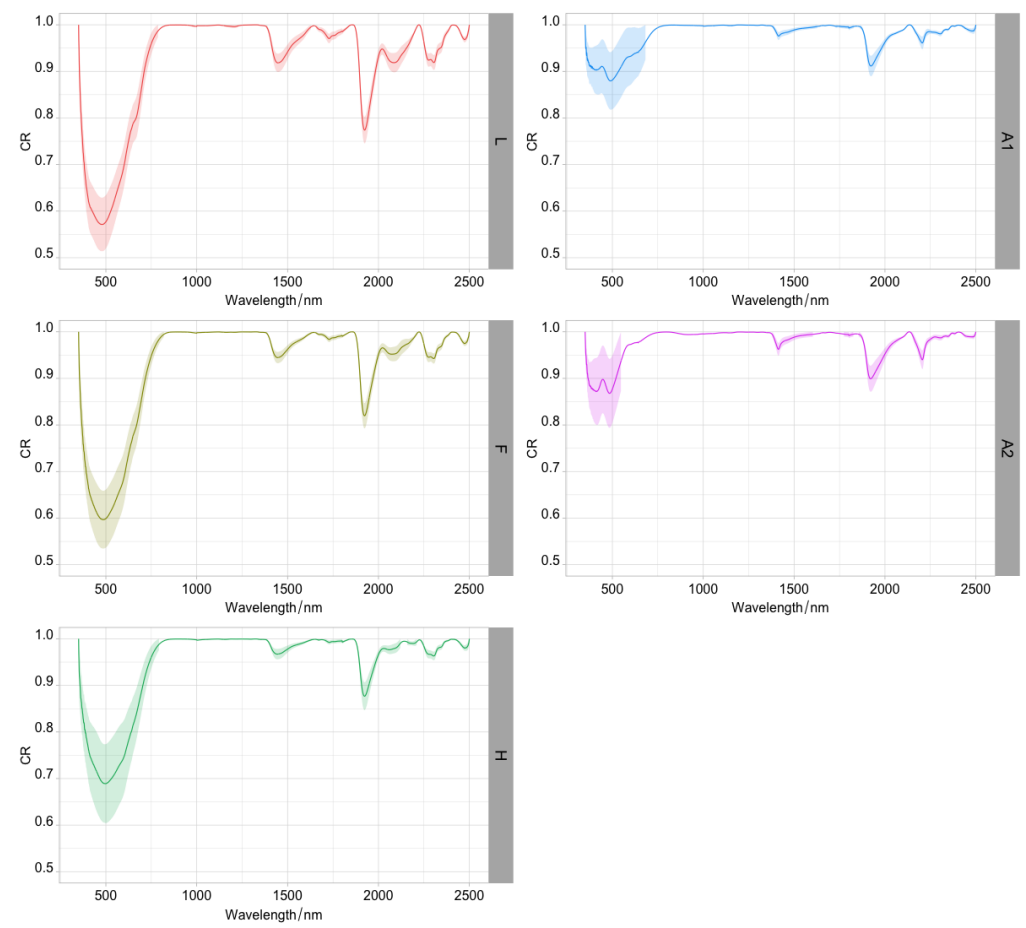

Figure 2: Continuum-removed spectra of forest soils for different horizons.

The spectra of horizons, particularly of those for L, F, and H, were simply related. They followed a progression which shows a reduction in the organic matter content. Compared with the spectra that represented small SOC contents (i.e., the mineral horizons), the spectra that represented high SOC (i.e., the organic horizons) reflected less and had a remarkably concave 
shape in the range of 400-1000 nm, which has been commonly seen in soils with abundant $\mathrm{C}$ content. The spectra for the mineral horizons $\mathrm{A}_{1}$ and $\mathrm{A}_{2}$ were typical of soils with higher mineral content and lower $\mathrm{C}$ concentration, with absorptions due to iron oxides, water, and clay minerals. Noticeable absorption features in the spectra of all target horizons can also be observed at the wavelengths $1400 \mathrm{~nm}, 1900 \mathrm{~nm}$ (Figure-2), and $2200 \mathrm{~nm}$, which are different depending on depth.

\subsection{Information Content of Forest Soil Spectra}

PCA was performed on the organic and mineral horizon soil spectra to investigate the differences in SOC variations at the target horizons (Figure 3).

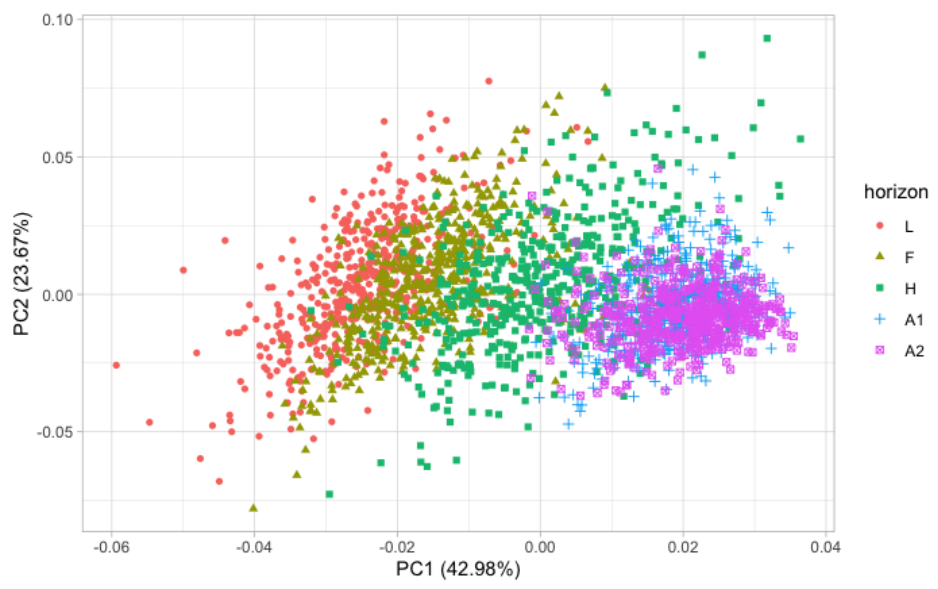

Figure 3: Scoreplot for the first two PCs in PCA analysis carried on SOC for different horizons.

As shown in Figure 3, the plot of $\mathrm{PC}_{1}$ and $\mathrm{PC}_{2}$, accounting for about $67 \%$ of variance, confirms that some samples were scattered away from the majority of the remaining samples, which were recognized as outliers and excluded from further investigation. The scoreplot of PCA indicates the 
data compression and its dimensionality reduction. As expected, there was an obvious separation of data (L, F, H, A 1 , and $\mathrm{A}_{2}$ ) by soil horizon (Figure 3). This occurred along the continuum of decomposition process, agreeing with what we had previously seen in the continuum-removed spectra (Figure 2).

The PCs of the data sets for each soil layer were different, as the samples from the organic and mineral horizons included different contents and types of SOC. The scores for the organic horizons L, F, and H occupied more PC space all over the plot, although mostly in the left half. Conversely, the mineral horizons $\left(A_{1}\right.$ and $\left.A_{2}\right)$ were particularly concentrated in the lower right half. Indeed, the results were different for $A_{1}$ and $A_{2}$, compared to the organic horizons (L, F, and H), as in the mineral horizons, some overlapping parts of the PCs were observed, which indicates that the data from $\mathrm{A}_{1}$ had some identical conditions to $\mathrm{A}_{2}$ in the corresponding feature space.

Figure 4 presents confusion matrix generated for the forest soil horizons classification using the SVM classifier, which delivers a visualization for the classification performance of spectral data for each soil horizon.

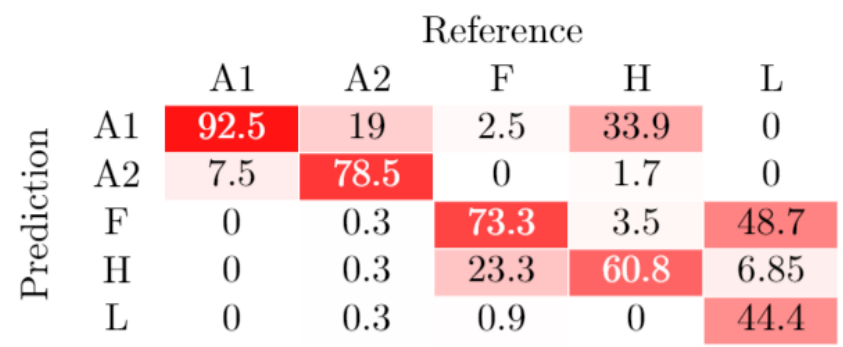

Figure 4: Confusion matrix percentage for soil horizons classification using SVM with national spectral data. 
The correctly classified cases and true positive rates are indicated in the diagonal of each matrix, although the misclassified cases and false negative rates are shown in the shaded grids outside the diagonal (Figure 4). The mineral horizons of $A_{1}$ and $A_{2}$ were the best classified horizons using visNIR spectroscopy with high true positive percentages of $92.5 \%$ and $78.5 \%$, respectively. However, the organic horizons, especially the layer L provided the lowest true positive percentage of $44.4 \%$. It can also be noticed that the highest false negative rate occurred for the horizon L, as $48.7 \%$ were classified as the $\mathrm{F}$ horizon.

The accuracy of the horizons classification was evaluated by Correct Classification Rate (CCR) and Kappa coefficient. The SVM with radial kernel had the potential to correctly classify forest soil horizons based on their spectra with CCR of $70 \%$ and Kappa coefficient of 0.63 for testing set.

\subsection{Spectroscopic Prediction of SOC Content}

Figure 5 highlights the results of the national SVM models for estimating SOC content at profile (organic and mineral horizons combined), combined organic, and combined mineral horizons of the Czech forest soils. The results of the prediction indicate that the national model developed for SOC at soil profile and combined organic horizon levels could be explained as providing good prediction accuracy, with $\mathrm{R}^{2}=0.76$ and 0.78 and $\mathrm{RMSE}=1.63 \%$ and $1.83 \%$, respectively (Figures 5A and 5B); however, the profile model was totally unbiased $(\mathrm{ME}=0 \%)$. The results for the SOC estimation in combined mineral horizons (Figure 5C), which contained considerably lower SOC content than the combined organic horizons, provided a relatively similar RMSE but a considerably lower $R^{2}$ value $\left(R^{2}=0.53\right)$. Nevertheless, according to 
Chang et al. (2001), the results for these horizons were still fair $\left(\mathrm{R}^{2}\right.$ between 0.5 and 0.7 ). In general, the model's performance under the combined organic and combined mineral horizons showed a descending trend as soil depths increased; however, the assessment statistics, in terms of the model biases and SDs (small values), indicated that the models were still capable of SOC prediction (Figure 5). According to Figure 5B, an equal distribution across the entire range of SOC is an advantage in model performance (Jaconi et al., 2019), which was the case for the whole profile and the combined organic horizons models.

For further assessment, we compared the estimated SOC content at individual layers for both organic and mineral horizons. A comparison of the scatterplots with predicted versus measured SOC for the five individual horizons $\left(\mathrm{L}, \mathrm{F}, \mathrm{H}, \mathrm{A}_{1}\right.$, and $\mathrm{A}_{2}$ ) is presented in Figure-6.

The estimation accuracy ranges were $\mathrm{R}^{2}=0.63-0.72$ and $\mathrm{RMSE}=0.98-$ $4.2 \%$ for individual horizons. Horizons $\mathrm{F}$ and $\mathrm{A}_{1}$ showed the best prediction results among the others, with higher $\mathrm{R}^{2}$ and lower ME (low-biased spatial estimates) values. We noted that these comparisons conformed well to the horizon spectral analysis shown in Figure-2. The predictions of SOC content from the other individual horizons $\left(\mathrm{L}, \mathrm{H}\right.$, and $\mathrm{A}_{2}$ ) also produced low error and $\mathrm{R}^{2}$, between 0.5 and 0.7 , despite their more scattered plots in the predicted to the measured values. There were no noticeable differences between the predictions of SOC in these horizons, in terms of their $\mathrm{R}^{2}$ and ME values, although the $\mathrm{H}$ horizon provided a higher RMSE (4.2\%) and was relatively more biased (Figure-6), which may be attributed to its higher SD (Table-3) as a higher SD results in larger RMSE value (Kuang \& Mouazen, 2011). 
It can also be seen that, in the individual organic horizons (L, F, and H), the RMSE increased with depth but, for all three layers, the RMSE values were somewhat smaller than the SDs of the SOC in the sampled soil profiles (Table 3 and Figure 6).
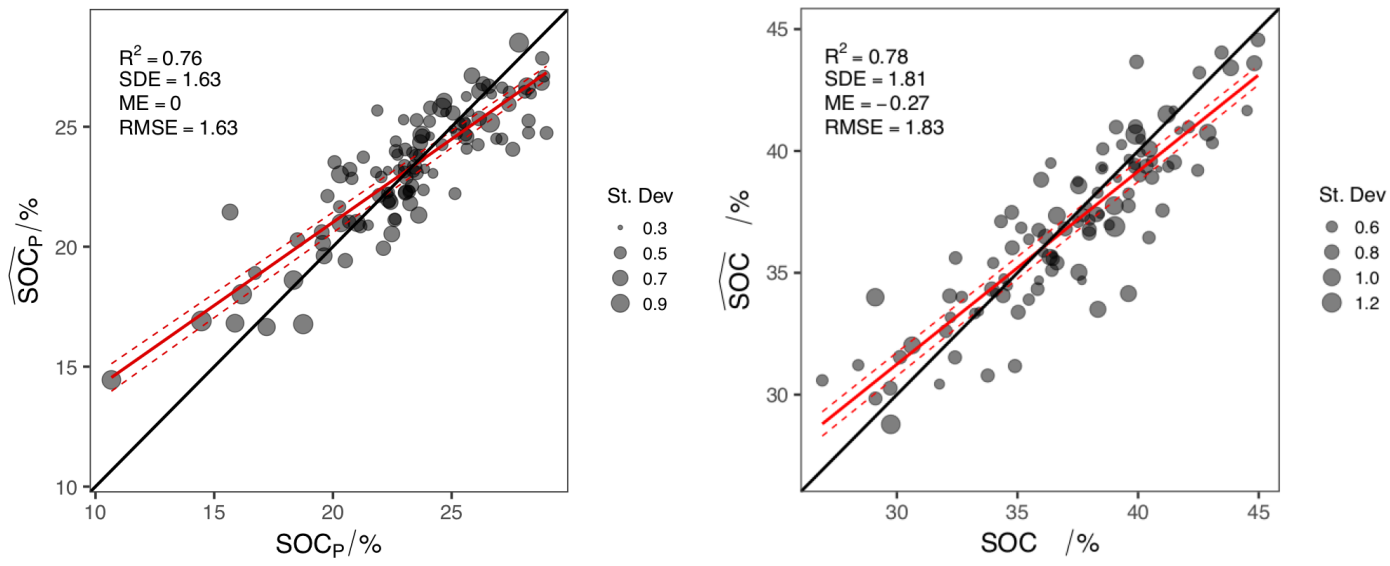

(A)

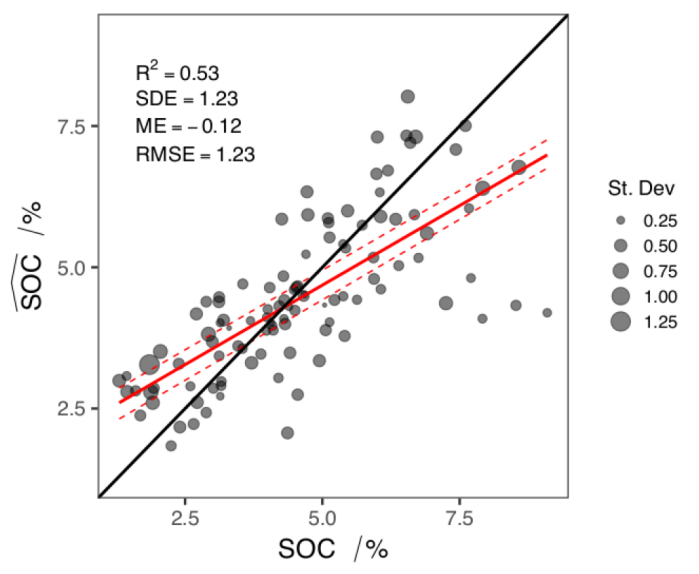

(B)

$(\mathrm{C})$

Figure 5: Predicted SOC plotted against measured SOC for profile (A), combined organic (B), and combined mineral (C) horizons in Czech forest soils. 


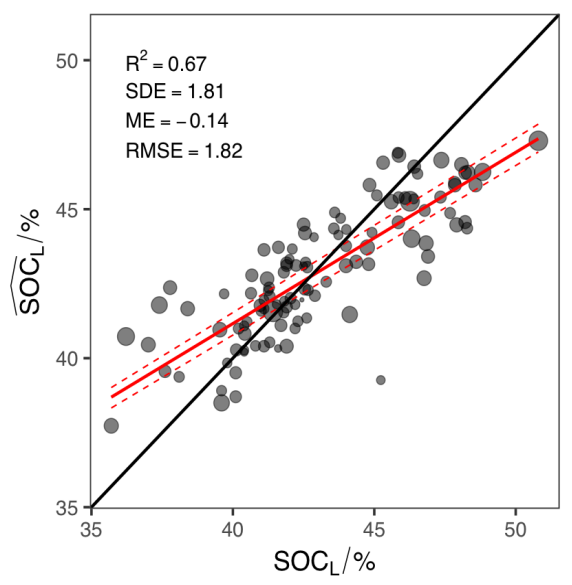

(A)

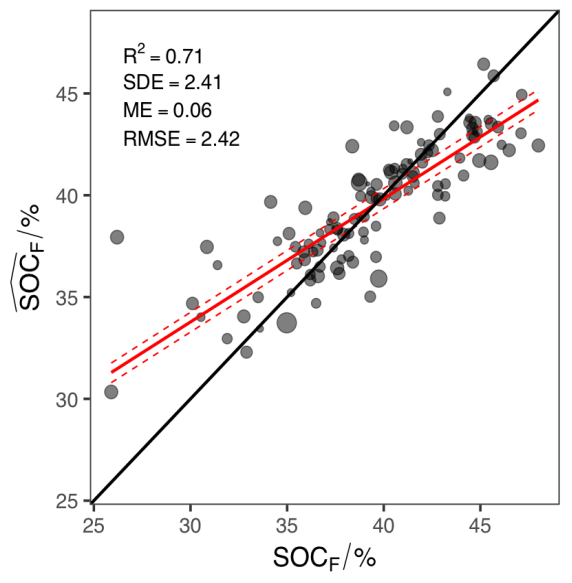

(B)

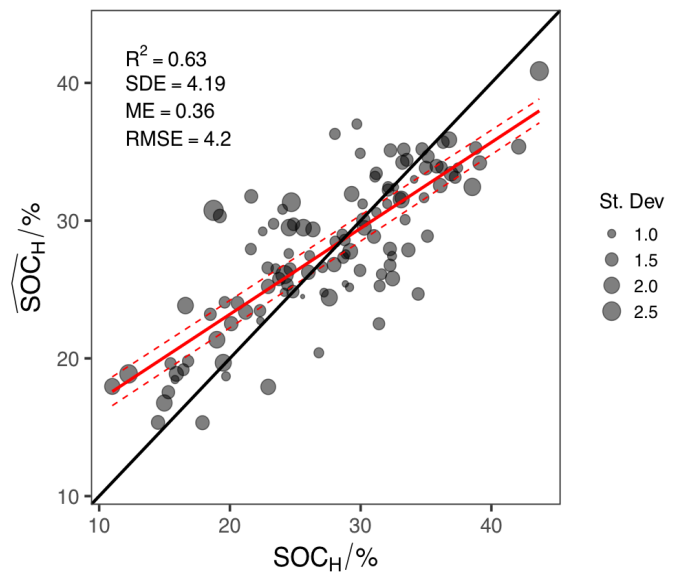

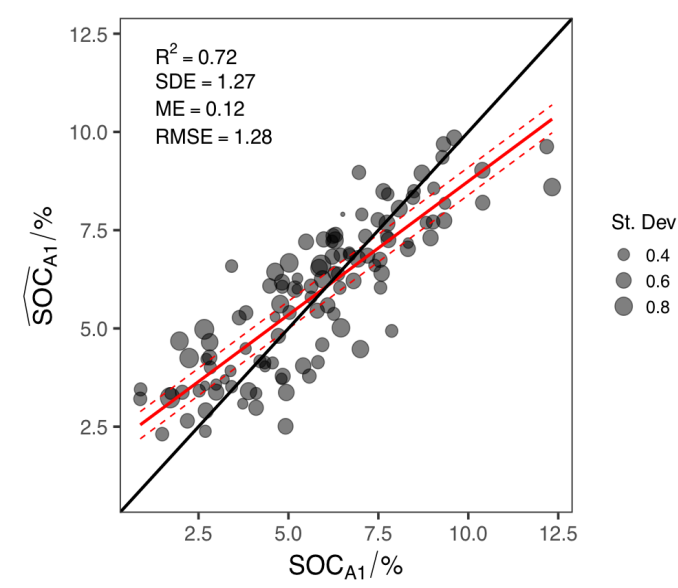

(D)

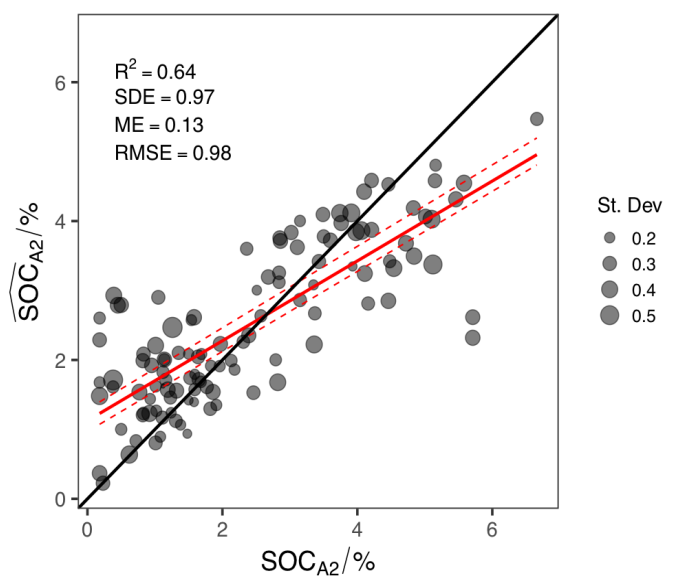

(E)

(C)

21

Figure 6: Predicted SOC plotted against measured SOC for L (A), F (B), H (C), A $(D)$, and $A_{2}(E)$ horizons in Czech forest soils. 
According to the results presented here, vis-NIR spectroscopy coupled with SVM could classify and predict the SOC at both organic and mineral horizons (together and individually) of forest soils at a national scale in the Czech Republic. The horizons classification was better performed in mineral horizons; however, the prediction accuracy was higher in organic horizons with shallower depth and considerably higher SOC content. The values of assessment metrics (CCR, Kappa coefficient, $\mathrm{R}^{2}$, RMSE, and ME) indicated that the SOC could be characterized and predicted well, whereas the accuracy for each horizon varied.

\section{Discussion}

The mean SOC content in our study (Table 3) showed that forest soils of the Czech Republic have high C storage in general (mean $=23.54 \%$ ), which decreases with depth. Jiang et al. (2017) mentioned that, over time, microorganisms gradually decompose the organic composition of litter, which enriches the top soils. In a study on different horizons of soil in Japanese forests, Ugawa et al. (2012) showed that soil C stock is usually decreased with depth as a result of $\mathrm{C}$ influx from decomposing litter and dead roots in the upper soil layer and low decomposition rates in the lower soil layer. Moreover, according to Verje et al. (2003) and Ping et al. (2010), in Cambisols, the most dominant soil class of the Czech Republic as well as in our sample set (Table1), there is little $\mathrm{C}$ under the organic horizons of these soils. They lack any significant soil development with depth, but can support thick organic rich surface horizons (Deluca \& Boisvenue, 2012). In general, our results of SOC content with depth (Table 3) were consistent with the prevailing trends in 
SOC depth distribution for soils across the globe (Li et al., 2015). Routh et al. (2016) showed a sharp decrease in SOC values of Swedish forests with increasing soil depth, from upper to lower horizons, and related it to lower rate of C sequestration in deeper soil layers. Jia et al. (2017), Wang et al. (2019), and Zhao et al. (2019) obtained similar results on vertical SOC patterns in different forested sites of China. They attributed it to reduction of below-ground plant biomass with soil depth, which has a considerable effect on SOC content. Table 3 also indicates the increase of SOC heterogeneity with depth, which was comparable with the conclusions of Hobley et al. (2018), who connected this large variance to high variability of SOC in lower horizons.

Soil spectral signature, like other soil properties, varies continuously and the resulting spectra represent complex compositional mixtures of soil materials from diverse origins, which are also affected by their environments. It is clear that vis-NIR spectra contain useful information about soil in general, and about SOC in particular (Gholizadeh et al., 2017), due to the different chemical bonds (Li et al., 2015). Figure 2 shows that all spectra, especially the L, F, and $\mathrm{H}$ horizon spectra, had a similar general form. They reflected less and had a concave shape in the range of 400-1000 nm, which has been shown to be typical for soils with high C content (Viscarra Rossel \& Hicks, 2015). The observed spectral features in the range of 400-1000 nm are indicative of iron and C concentration (Sherman \& Waite, 1985). The spectral patterns of horizons $\mathrm{L}$ and $\mathrm{F}$, with accumulation of less-decomposed organic matter (e.g. leaves, needles, and little branches) in this range $(400-1000 \mathrm{~nm})$ are mainly functions of the remaining photosynthetic pigments (e.g. chloro- 
phyll, carotenoids, and xanthophylls) and cell structures (Gitelson et al., 2002). These results mirrored the results of Ogen et al. (2017), who used the vis-NIR range for soil classification and concluded that the accumulated roots and other plant residuals at upper soil layers affected the soil spectral pattern. In the NIR range, at the wavelengths $1400 \mathrm{~nm}, 1900 \mathrm{~nm}$, and $2200 \mathrm{~nm}$, there were sharp absorption bands that resulted from overtones and combination vibrations of the organic functional groups methyl, methylene and aryl, carbonyl, ester and carboxyl $\mathrm{C}=\mathrm{O}$, cellulose $\mathrm{C}-\mathrm{C} / \mathrm{C}-\mathrm{H}, \mathrm{C}-\mathrm{H}$, and O-H groups (Viscarra Rossel \& Hicks, 2015). Ben-Dor \& Banin (1995) also mentioned that absorption at these specific wavelengths $(1400 \mathrm{~nm}, 1900 \mathrm{~nm}$, and $2200 \mathrm{~nm}$ ) are generally associated with minerals and water bound in the interlayer lattices. However, the process of air-drying and soil grinding reduced the absorbance spectra and amplitude characteristic peaks (Jia et al., 2017). Buitrago et al. (2016) and Gholizadeh \& Kopackova (2019) stated that the dominant factors controlling the pattern of vegetation spectra at these wavelengths (for organic horizons $\mathrm{L}$ and $\mathrm{F}$, with mostly plant matter) are the biochemical constituents of fresh plants (e.g. lignin, cellulose, starch, and protein). The soil horizon colour, which varies due to soil organic matter content (Ben-Dor et al., 2008) and structure (Zanella et al., 2017), can also influence soil spectra (Gholizadeh et al., 2020). This is probably the reason for the general strong absorption peaks in horizon H (Figure 2), which had a very dark colour and a fine and well-decomposed structure (Zanella et al., 2017).

The plot of the PCA scores shows that SOC was coherent with differences in its content and variability, although the results were quite different 
between shallower samples in organic horizons and deeper samples in mineral horizons (Figure 3). This may be consistent with the variation of SOC values in the samples. There are also likely complex interactions reflecting pedogenesis processes behind this and in this regard, the forest soils (as major sources of C) go beyond simple soil types and classes and are, thus, suitable for showing variations in SOC content properly. In order to confirm these findings, the potential of the SVM classifier for classification of forest soil organic and mineral horizons based on their vis-NIR spectra was performed, which provided promising discrimination among all studied horizons. SVMbased classification can actually strike balance between acquired from a given finite amount of training patterns and the ability to generalize to unseen data (Mountrakis et al., 2011).

According to the prediction statistics for the vis-NIR spectra of the soil profile, the combined organic and combined mineral horizons, as well as their individual layers (Figures 5 and 6), it was apparent that, in general, the prediction capability was weakened (lower $\mathrm{R}^{2}$ and relatively similar error) with increasing depth. This is presumably because the spectral reflectance from the soil becomes less effective as a predictor regarding the sharp decline of SOC concentration (Jia et al., 2017). However, in spite of this descending trend, the technique still cost-effectively estimated SOC concentration, even in deeper horizons of forested sites. At a large scale (i.e., regional or global), the relationships between the soil spectra and soil properties are usually spatially dependent (Hong et al., 2018), which limits the efficiency of spectroscopic models over large areas (Liu et al., 2019). Given such variation at a large national scale, our results were comparable with the results 
of some previous studies on different soil types and geographical scales (Li et al., 2015; Viscarra Rossel et al., 2016; Jia et al., 2017), though the statistical metrics of the aforementioned studies showed broad ranges. Regarding the important criteria of geographical scale of the research (i.e., field, local, regional, or national), it should be noted that soil spectroscopic models established in local-scale studies usually performed better (Stevens et al., 2013; Guerrero et al., 2016), possibly because soils sampled at a local scale have lower variability and more similar spectral features.

Considering SOC prediction in individual horizons (Figure 6), superior results for horizons $\mathrm{F}$ and $\mathrm{A}_{1}$ can be noticed, with higher $\mathrm{R}^{2}$ and lower $\mathrm{ME}$ (low-biased spatial estimates) than other target horizons. This can probably be explained by expanding our knowledge about the possible contribution of SOC type, as well as its correlation with other available soil properties in these horizons, which has been reported in some studies (Telles et al., 2003; Gholizadeh et al., 2018). Horizon $\mathrm{H}$ had the highest RMSE (4.2\%), along with the highest SD value among others (Table 3), which was noticeable in Figure-6C. According to research by Kuang \& Mouazen (2011) and Jia et al. (2017), high SD and variability in the range of SOC content are crucial factors affecting the accuracy of calibration models. Therefore, their results, similarly to ours, highlighted that a larger SD and wider range explained the variability of SOC content and led to a larger RMSE. This is in contrast with Gaudinski et al. (2000), who stated that, as the residence time of SOC enhances with depth, the maximum changes and higher SDs are more likely to occur in the organic horizons. In the current study, the RMSE in organic horizons increased with depth, although it was smaller than the SDs of the 
SOC in the sampled soil profiles. These results agree with the findings of Viscarra Rossel et al. (2016) at three soil depths across grazing lands.

Overall, this study provides an example of how general pedological knowledge can be used to define depth functions of SOC for forested sites. Importantly, the outcomes of this work indicate that vis-NIR reflectance spectroscopy, as an effective technique, could rapidly and cost-effectively classify forest soil horizons and also predict SOC content at a large number of national-scale samples from the upper to lower horizons. The technique allows us to create massive soil depth data, which can facilitate SOC mapping, accounting, and management. This information is not typically available through conventional approaches.

\section{Conclusions}

SOC in forest varies by depth due to different decomposition rates, which has a significant influence on total $\mathrm{C}$ pool alteration and, therefore, on detachment of SOC, atmospheric $\mathrm{CO}_{2}$ concentration, and climate change mitigation. This study showed that there was a large variation in SOC content among the forest soil horizons (from $42.91 \%$ in $\mathrm{L}$ to $2.74 \%$ in $\mathrm{A}_{2}$ ), depending on the depth from which the samples were derived and, further, due to the most dominant soil class of the study area (Cambisols), which are soils with little $\mathrm{C}$ under the organic horizons. Soil spectra forms and trends were generally similar across the horizons, particularly in the L, F, and $\mathrm{H}$ layers; however, the spectra of horizon $\mathrm{H}$ showed noticeably stronger absorption peaks, probably because of its darker colour and well-decomposed structure. The soil horizons were satisfactorily characterized with accuracy of CCR $=$ 
$70 \%$ using their reflectance spectra. The SOC spectroscopic models of the combined organic horizons were more accurate than those of the combined mineral horizons. The prediction accuracy of the models based on the individual horizons $\mathrm{F}$ and $\mathrm{A}_{1}$ were greater than the others, with $\mathrm{R}^{2}$ values higher than 0.70 and low-biased spatial estimates. However, SOC content in horizons $\mathrm{L}, \mathrm{H}$, and $\mathrm{A}_{2}$ were also well-estimated, with low error and $\mathrm{R}^{2}>0.63$. The findings of the current study indicate that vis-NIR spectroscopy coupled with SVM could characterize and predict SOC content of different horizons across the forests of the Czech Republic, which are representative of the forests of temperate Europe.

\section{Acknowledgement}

The authors like to thank the financial support of the Czech Science Foundation (project No. 18-28126Y). The authors also thank the Central Institute for Supervising and Testing in Agriculture for providing the samples and data. The kind assistance of Mr. Karel Nemecek for providing the detailed study area map is greatly appreciated.

\section{References}

Barcena, T. G., Gundersen, P., \& Vesterdal, L. (2014). Afforestation effects on soc in former cropland: oak and spruce chronosequences resampled after 13 years. Global Change Biology, 20, 2938-2952.

Batjes, N. H. (1996). Total carbon and nitrogen in the soils of the world. Eur. J. Soil Sci., 47, 151-163. 
Bellamy, P. H., Loveland, P. J., Bradley, R. I., Lark, R. M., \& Kirk, G. J. D. (2005). Carbon losses from all soils across england and wales 1978-2003. Nature, 437, 245-248.

Bellassen, V., \& Luyssaert, S. (2014). Carbon sequestration: Managing forests in uncertain times. Nature, 506, 153-155. doi:10.1038/506153a.

Bellon-Maurel, V., Fernandez-Ahumada, E., Palagos, B., Roger, J.-M., \& McBratney, A. (2010). Critical review of chemometric indicators commonly used for assessing the quality of the prediction of soil attributes by nir spectroscopy. TrAC Trends in Analytical Chemistry, 29, 1073 - 1081. doi:10.1016/j.trac.2010.05.006.

Ben-Dor, E., \& Banin, A. (1995). Near-Infrared Analysis as a Rapid Method to Simultaneously Evaluate Several Soil Properties. Soil Science Society of America Journal, 59. doi:10.2136/sssaj1995.03615995005900020014x.

Ben-Dor, E., Heller, D., \& Chudnovsky, A. (2008). A Novel Method of Classifying Soil Profiles in the Field using Optical Means. Soil Science Society of America Journal, 72, 1113-1123. doi:10.2136/sssaj2006.0059.

Black, K., Creamer, R. E., Xenakis, G., \& Cook, S. (2014). Improving forest soil carbon models using spatial data and geostatistical approaches. Geoderma, 232, 487-499. doi:10.1016/j.geoderma.2014.05.022.

Brahma, B., Pathak, K., Lal, R., Kurmi, B., Das, M., Nath, P. C., Nath, A. J., \& Das, A. K. (2018). Ecosystem carbon sequestration through restoration of degraded lands in Northeast India. Land Degradation $\&$ Development, 29, 15-25. doi:10.1002/ldr.2816. 
Buitrago, M., Groen, T., Hecker, C., \& Skidmore, A. (2016). Changes in thermal infrared spectra of plants caused by temperature and water stress. ISPRS Journal of Photogrametry Remote Sensing, 111, 22-31.

Chamberlain, P. M., Emmett, B. A., Scott, W. A., Black, H. I. J., Hornung, M., \& Frogbrook, Z. L. (2010). No change in topsoil carbon levels of great britain, 1978-2007. Biogeosciences Discussions, 7, 2267-2311. doi:10.5194/bgd-7-2267-2010.

Chang, C., Laird, M., D.A.and Mausbach, \& Hurburgh Jr., C. (2001). Nearinfrared reflectance spectroscopy - principal component analysis of soil properties. Soil Science Society America Journal, 65, 480-480.

Cienciala, E., Exnerova, Z., \& Schelhaas, M.-J. (2008). Development of forest carbon stock and wood production in the Czech Republic until 2060. Annals of Forest Science, 65, 603-603. doi:10.1051/forest:2008043.

Clark, R., \& Roush, T. (1984). Reectance spectroscopy: quantitative analysis techniques for remote sensing applications. Journal of Geophysical Research, 89, 6329-6340.

Conen, F., Zerva, A., Arrouays, D., Jolivet, P., C.and Jarvis, Grace, J., \& Mencuccini, M. (2004). The carbon balance of forest soils; detectability of changes in soil carbon stocks in temperate and boreal forests. In H. Griffith, \& P. Jarvis (Eds.), The carbon balance of forest biomes. Oxford: Bios Scientific Press.

Cook, R. (1977). Detection of inuential observation in linear regression. Technometrics, 19, 15-18. 
Czech Statistical Office (2019). Surveying, mapping and cadastre. URL: https://vdb.czso.cz.

Deluca, T. H., \& Boisvenue, C. (2012). Boreal forest soil carbon: distribution, function and modelling. Forestry: An International Journal of Forest Research, 85, 161-184. doi:10.1093/forestry/cps003.

Dotto, A. C., Dalmolin, R. S. D., Caten, A. t., \& Grunwald, S. (2018). A systematic study on the application of scatter-corrective and spectral-derivative preprocessing for multivariate prediction of soil organic carbon by Vis-NIR spectra. Geoderma, 314, 262-274. doi:10.1016/j.geoderma.2017.11.006.

Ellert, B., Janzen, H., \& McConkey, B. (2001). Measuring and comparing soil carbon storage. In Assessment methods for soil carbon chapter 10. CRC.

England, J. R., \& Viscarra Rossel, R. A. (2018). Proximal sensing for soil carbon accounting. SOIL Discussions, (pp. 1-32). doi:10.5194/soil-201736.

Fan, S., Guan, F., Xu, X., Forrester, D. I., Ma, W., \& Tang, X. (2016). Ecosystem carbon stock loss after land use change in subtropical forests in china. Forests, \% doi:10.3390/f7070142.

Fernandez-Romero, M., Lozano-Garcia, B., \& Parras-Alcantara, L. (2014). Topography and land use change effects on the soil organic carbon stock of forest soils in mediterranean natural areas. Agriculture, Ecosystems Environment, 195, 1 - 9. doi:https://doi.org/10.1016/j.agee.2014.05.015. 
Fiala, P., Reininger, D., Samek, T., Nemec, P., \& Susil, A. (2013). Pruzkum vyzivy lesa na uzemi Ceske republiky 1996 2011.. Technical Report.

Gaudinski, J. B., Trumbore, S. E., Davidson, E. A., \& Zheng, S. (2000). Soil carbon cycling in a temperate forest: radiocarbon-based estimates of residence times, sequestration rates and partitioning of fluxes. Biogeochemistry, 51, 33-69. doi:10.1023/A:1006301010014.

Gholizadeh, A., Boruvka, L., Saberioon, M., \& Vasat, R. (2016). A MemoryBased Learning Approach as Compared to Other Data Mining Algorithms for the Prediction of Soil Texture Using Diffuse Reflectance Spectra. Remote sensing, 8. doi:10.3390/rs8040341.

Gholizadeh, A., Carmon, N., Klement, A., Ben-Dor, E., \& Boruvka, L. (2017). Agricultural Soil Spectral Response and Properties Assessment: Effects of Measurement Protocol and Data Mining Technique. Remote Sensing, 9, 1078. doi:10.3390/rs9101078.

Gholizadeh, A., \& Kopackova, V. (2019). Detecting vegetation stress as a soil contamination proxy: a review of optical proximal and remote sensing techniques. International Journal of Environmental Science and Technology, 16, 2511-2524. doi:10.1007/s13762-019-02310-w.

Gholizadeh, A., Saberioon, M., Rossel, R. A. V., Boruvka, L., \& Klement, A. (2020). Spectroscopic measurements and imaging of soil colour for field scale estimation of soil organic carbon. Geoderma, 357, 113972. doi:10.1016/j.geoderma.2019.113972. 
Gholizadeh, A., Zizala, D., Saberioon, M., \& Boruvka, L. (2018). Soil organic carbon and texture retrieving and mapping using proximal, airborne and Sentinel-2 spectral imaging. Remote Sensing of Environment, 218, 89-103. doi:10.1016/j.rse.2018.09.015.

Gibson, T., Chan, K., Sharma, G., \& Shearman, R. (2002). Soil Carbon Sequestration Utilising Recycled Organics. Technical Report.

Gitelson, A., Zur, Y., Chivkunova, O., \& Merzlyak, M. (2002). Assessing carotenoid content in plant leaves with reflectance spectroscopy. Photochemistry and Photobiology, 75, 272-281.

Goidts, E., Van Wesemael, B., \& Crucifix, M. (2009). Magnitude and sources of uncertainties in soil organic carbon ( $\mathrm{soc}$ ) stock assessments at various scales. European Journal of Soil Science, 60, 723-739. doi:10.1111/j.13652389.2009.01157.x.

Gomez, C., Gholizadeh, A., Boruvka, L., \& Lagacherie, P. (2016). Using legacy data for correction of soil surface clay content predicted from VNIR/SWIR hyperspectral airborne images. Geoderma, 276, 84-92. doi:10.1016/j.geoderma.2016.04.019.

Griffiths, R. P., \& Madritch, A. K., M. D.and Swanson (2009). The effects of topography on forest soil characteristics in the oregon cascade mountains (usa): implications for the effects of climate change on soil properties. Forest Ecology and Management, 257, 1-7.

Guerrero, C., Wetterlind, J., Stenberg, B., Mouazen, A. M., GabarronGaleote, M. A., Ruiz-Sinoga, J. D., Zornoza, R., \& Rossel, R. A. V. 
(2016). Do we really need large spectral libraries for local scale soc assessment with nir spectroscopy? Soil and Tillage Research, 155, 501 509. doi:https://doi.org/10.1016/j.still.2015.07.008.

Hastie, T., Tibshirani, R., \& Friedman, J. (2009). The Elements of Statistical Learning: Data Mining, Inference and Prediction. New York, NY, USA: Springer.

Hobley, E., Steffens, M., Bauke, S. L., \& Kogel-Knabner, I. (2018). Hotspots of soil organic carbon storage revealed by laboratory hyperspectral imaging. Scientific Reports, 8, 13900. doi:10.1038/s41598-018-31776-w.

Hong, Y., Chen, Y., Zhang, Y., Liu, Y., Liu, Y., Yu, L., Liu, Y., \& Cheng, H. (2018). Transferability of vis-nir models for soil organic carbon estimation between two study areas by using spiking. Soil Science Society of America Journal, 82, 1231. doi:10.2136/sssaj2018.03.0099.

Hutengs, C., Seidel, M., Oertel, F., Ludwig, B., \& Vohland, M. (2019). In situ and laboratory soil spectroscopy with portable visible-to-near-infrared and mid-infrared instruments for the assessment of organic carbon in soils. Geoderma, 355, 113900. doi:10.1016/j.geoderma.2019.113900.

IPCC (2000). Land use, land-use change, and forestry. (p. 375). Cambridge: Cambridge University Press.

IUSS Working Group WRB (2015). World Reference Base for Soil Resources 2014, update 2015: International Soil Classication System for Naming Soils and Creating Legends for Soil Maps. Technical Report FAO. 
Jaconi, A., Poeplau, C., RamirezLopez, L., Wesemael, B. V., \& Don, A. (2019). Logratio transformation is the key to determining soil organic carbon fractions with nearinfrared spectroscopy. European Journal of Soil Science, 70, 127-139. doi:10.1111/ejss.12761.

Jensen, J. (2007). Remote Sensing of the Environment: An Earth Resource Perspective volume 544. Prentice Education.

Jia, X., Chen, S., Yang, Y., Zhou, L., Yu, W., \& Shi, Z. (2017). Organic carbon prediction in soil cores using VNIR and MIR techniques in an alpine landscape. Scientific Reports, 7, 2144. doi:10.1038/s41598-017-02061-z.

Jian-Bing, W., Du-Ning, X., Xing-Yi, Z., Xiu-Zhen, L., \& Xiao-Yu, L. (2006). Spatial variability of soil organic carbon in relation to environmental factors of a typical small watershed in the black soil region, northeast china. Environmental Monitoring and Assessment, 121, 597-613. doi:10.1007/s10661-005-9158-5.

Jiang, Q., Li, Q., Wang, X., Wu, Y., Yang, X., \& Liu, F. (2017). Estimation of soil organic carbon and total nitrogen in different soil layers using VNIR spectroscopy: Effects of spiking on model applicability. Geoderma, 293, 54-63. doi:10.1016/j.geoderma.2017.01.030.

Kim, M. G. (2017). A cautionary note on the use of Cook's distance. Communications for Statistical Applications and Methods, 24, 317-324. doi:10.5351/csam.2017.24.3.317.

Kirwan, N., Oliver, M. A., Moffat, A. J., \& Morgan, G. W. (2005). Sampling the soil in long-term forest plots: The implications of spa- 
tial variation. Environmental Monitoring and Assessment, 111, 149-172. doi:10.1007/s10661-005-8219-0.

Knadel, M., Deng, F., \& Thomsen, M., A.and Greve (2012). Development of a danish national visnir soil spectral library for soil organic carbon determination. In B. Minasny, B. P. Malone, \& A. B. McBratney (Eds.), Digital Soil Assessments and Beyond: Proceedings of the 5th Global Workshop on Digital Soil Mapping 2012. CRC Press.

Kooistra, L., Wanders, J., Epema, G., Leuven, R., Wehrens, R., \& Buydens, L. (2003). The potential of field spectroscopy for the assessment of sediment properties in river floodplains. Analytica Chimica Acta, 484, 189-200. doi:10.1016/s0003-2670(03)00331-3.

Kuang, B., \& Mouazen, A. M. (2011). Calibration of visible and near infrared spectroscopy for soil analysis at the field scale on three european farms. European Journal of Soil Science, 62, 629-636. doi:10.1111/j.13652389.2011.01358.x.

Lal, R. (2004). Soil Carbon Sequestration Impacts on Global Climate Change and Food Security. Science, 304, 1623-1627. doi:10.1126/science.1097396.

Lal, R. (2008). Carbon sequestration in soil. CAB Reviews: Perspectives in Agriculture, Veterinary Science, Nutrition and Natural Resources, 3. doi:10.1079/pavsnnr20083030.

Lal, R. (2016). Soil health and carbon management. Food and Energy Security, 5, 212-222. doi:10.1002/fes3.96. 
Lal, R. (2017). Carbon Management, Technologies, and Trends in Mediterranean Ecosystems, . 15, 1-11. doi:10.1007/978-3-319-45035-3_1.

Li, S., Shi, Z., Chen, S., Ji, W., Zhou, L., Yu, W., \& Webster, R. (2015). In Situ Measurements of Organic Carbon in Soil Profiles Using vis-NIR Spectroscopy on the QinghaiTibet Plateau. Environmental Science $\&$ Technology, 49, 4980-4987. doi:10.1021/es504272x.

Liu, S., Shen, H., Chen, S., Zhao, X., Biswas, A., Jia, X., Shi, Z., \& Fang, J. (2019). Estimating forest soil organic carbon content using vis-NIR spectroscopy: Implications for large-scale soil carbon spectroscopic assessment. Geoderma, 348, 37-44. doi:10.1016/j.geoderma.2019.04.003.

Lorenz, K., \& Lal, R. (2014). Soil organic carbon sequestration in agroforestry systems. a review. Agronomy for Sustainable Development, 34 , 443-454. doi:10.1007/s13593-014-0212-y.

Martens, H., \& Naes, T. (1992). Multivariate Calibration. John Wiley Sons, New York, USA.

Mouazen, A. M., Baerdemaeker, J. D., \& Ramon, H. (2005). Towards development of on-line soil moisture content sensor using a fibre-type nir spectrophotometer. Soil and Tillage Research, 80, 171 - 183. doi:https://doi.org/10.1016/j.still.2004.03.022.

Mountrakis, G., Im, J., \& Ogole, C. (2011). Support vector machines in remote sensing: A review. ISPRS Journal of Photogrammetry and Remote Sensing, 66 . 
Ogen, Y., Goldshleger, N., \& Ben-Dor, E. (2017). 3D spectral analysis in the VNIRSWIR spectral region as a tool for soil classification. Geoderma, 302, 100-110. doi:10.1016/j.geoderma.2017.04.020.

Palmer, C. J., Smith, W. D., \& Conkling, B. L. (2002). Development of a protocol for monitoring status and trends in forest soil carbon at a national level. Environmental Pollution, 116, 209-219.

Ping, C. L., Michaelson, G. J., Kane, E. S., Packee, E. C., Stiles, C. A., Swanson, D. K., \& Zaman, N. D. (2010). Carbon Stores and Biogeochemical Properties of Soils under Black Spruce Forest, Alaska. Soil Science Society of America Journal, 74, 969. doi:10.2136/sssaj2009.0152.

Routh, J., Bianchi, T. S., Hutchings, J. A., Kuhry, P., \& Ranjan, R. K. (2016). Organic carbon characteristics in Swedish forest soil trace postdepositional carbon dynamics. European Journal of Soil Science, 67, 492503. doi:10.1111/ejss. 12358 .

Saberioon, M., Csa, P., Labb, L., Souek, P., Pelissier, P., \& Kerneis, T. (2018). Comparative Performance Analysis of Support Vector Machine, Random Forest, Logistic Regression and k-Nearest Neighbours in Rainbow Trout (Oncorhynchus Mykiss) Classification Using Image-Based Features. Sensors, 18, 1027. doi:10.3390/s18041027.

Saby, N., \& Arrouays, D. (2004). Simulation of the use of a soil-monitoring network to verify carbon sequestration in soils: Will changes in organic carbon stocks be detectable? Communications in Soil Science and Plant Analysis, 35, 2379-2396. doi:10.1081/LCSS-200030313. 
Savitzky, A., \& Golay, M. (1964). Smoothing and differentiation of data by simplified least squares procedures. Analytical Chemistry, 36, 1627-1639.

Schlesinger, W. H. (1995). Soil respiration and changes in soil carbon stocks. In M. F. Woodwell, G.M. (Ed.), Biotic Feedbacks from the Warming of the Earth chapter 8. (pp. 159-168). Oxford University Press, Inc.

Sherman, D., \& Waite, T. (1985). Electronic spectra of fe3+ oxides and oxyhydroxides in the near infrared to ultraviolet. American Mineralogist, 70, 1262-1269.

Shi, T., Wang, J., Chen, Y., \& Wu, G. (2016). Improving the prediction of arsenic contents in agricultural soils by combining the reflectance spectroscopy of soils and rice plants. International Journal of Applied Earth Observation and Geoinformation, 52, 95 - 103. doi:https://doi.org/10.1016/j.jag.2016.06.002.

Smith, P. (2008). Land use change and soil organic carbon dynamics. Nutrient Cycling in Agroecosystems, 81, 169-178. doi:10.1007/s10705-007-9138y.

Sparks, D. (1996). Methods of Soil Analysis. Part 3 Chemical Methods.. Madison, WI, USA: Soil Science Society of America, American Society of Agronomy.

Stenberg, B., Viscarra Rossel, R. A., Mouazen, A. M., \& Wetterlind, J. (2010). Chapter five - visible and near infrared spectroscopy in soil science. (pp. 163 - 215). Academic Press volume 107 of Advances in Agronomy. doi:https://doi.org/10.1016/S0065-2113(10)07005-7. 
Stevens, A., Nocita, M., Toth, G., Montanarella, L., \& van Wesemael, B. (2013). Prediction of soil organic carbon at the european scale by visible and near infrared reflectance spectroscopy. PLOS ONE, 8, 1-13. doi:10.1371/journal.pone.0066409.

Telles, E. d. C. C., de Camargo, P. B., Martinelli, L. A., Trumbore, S. E., da Costa, E. S., Santos, J., Higuchi, N., \& Oliveira Jr., R. C. (2003). Influence of soil texture on carbon dynamics and storage potential in tropical forest soils of amazonia. Global Biogeochemical Cycles, 17. doi:10.1029/2002GB001953.

Ugawa, S., Takahashi, M., Morisada, K., Takeuchi, M., Yoshinaga, S., Araki, M., Tanaka, N., Ikeda, S., Matsuura, Y., Miura, S., Ishizuka, S., Kobayashi, M., Inagaki, M., Imaya, A., Nanko, K., Hashimoto, S., Aizawa, S., Hirai, K., Okamoto, T., Mizoguchi, T., Torii, A., Sakai, H., Ohnuki, Y., \& Kaneko, S. (2012). Carbon stocks of dead wood, litter, and soil in the forest sector of Japan :general description of the National Forest Soil Carbon Inventory. Bulletin of FFPRI, 11, 207-221.

Vanguelova, E. I., Bonifacio, E., Vos, B. D., Hoosbeek, M. R., Berger, T. W., Vesterdal, L., Armolaitis, K., Celi, L., Dinca, L., Kjnaas, O. J., Pavlenda, P., Pumpanen, J., Puttsepp, ., Reidy, B., Simoncic, P., Tobin, B., \& Zhiyanski, M. (2016). Sources of errors and uncertainties in the assessment of forest soil carbon stocks at different scalesreview and recommendations. Environmental Monitoring and Assessment, 188, 630. doi:10.1007/s10661016-5608-5. 
Vapnik, V. (1998). Statistical Learning Theory. New York, NY, USA: WileyInterscience.

Verje, H., Callesen, L., I.and Vesterdal, \& Raulund-Rasmussen, K. (2003). Carbon and nitrogen in danish forest soils-contents, distribution determined by soil order. Soil Science Society of America Journal, 67, 335-343.

Viscarra Rossel, R. (2007). Robust modelling of soil diffuse reflectance spectra by bagging partial least squares regression. Journal of Near Infrared Spectroscopy, 15, 39-47.

Viscarra Rossel, R., Brus, D., Lobsey, C., Shi, Z., \& McLachlan, G. (2016). Baseline estimates of soil organic carbon by proximal sensing: Comparing design-based, model-assisted and model-based inference. Geoderma, 265, 152-163. doi:10.1016/j.geoderma.2015.11.016.

Viscarra Rossel, R., McGlynn, R., \& McBratney, A. (2006). Determining the composition of mineral-organic mixes using UVvisNIR diffuse reflectance spectroscopy. Geoderma, 137, 70-82. doi:10.1016/j.geoderma.2006.07.004.

Viscarra Rossel, R., \& Webster, R. (2012). Predicting soil properties from the Australian soil visiblenear infrared spectroscopic database. European Journal of Soil Science, 63, 848-860. doi:10.1111/j.1365-2389.2012.01495.x.

Viscarra Rossel, R. A., \& Behrens, T. (2010). Using data mining to model and interpret soil diffuse reflectance spectra. Geoderma, 158, 46-54. doi:10.1016/j.geoderma.2009.12.025. 
Viscarra Rossel, R. A., \& Lark, R. M. (2009). Improved analysis and modelling of soil diffuse reflectance spectra using wavelets. European Journal of Soil Science, 60, 453-464. doi:10.1111/j.1365-2389.2009.01121.x.

Viscarra Rossel, R. A., Lee, J., Behrens, T., Luo, Z., Baldock, J., \& Richards, A. (2019). Continental-scale soil carbon composition and vulnerability modulated by regional environmental controls. Nature Geoscience, 12, 547-552. doi:10.1038/s41561-019-0373-z.

Viscarra Rossel, R. A., Lobsey, C. R., Sharman, C., Flick, P., \& McLachlan, G. (2017). Novel soil profile sensing to monitor organic C stocks and condition. Environmental Science \& Technology, . doi:10.1021/acs.est.7b00889.

Viscarra Rossel, R. A. V., \& Hicks, W. S. (2015). Soil organic carbon and its fractions estimated by visiblenear infrared transfer functions. European Journal of Soil Science, 66, 438-450. doi:10.1111/ejss.12237.

Wang, Y., Jiang, J., Niu, Z., Li, Y., Li, C., \& Feng, W. (2019). Responses of soil organic and inorganic carbon vary at different soil depths after longterm agricultural cultivation in Northwest China. Land Degradation \& Development, 30, 1229-1242. doi:10.1002/ldr.3311.

Webster, K. L., Creed, F. D., I. F.and Beall, \& Bourbonniere, R. A. (2011). A topographic template for estimating soil carbon pools in forested catchments. Geoderma, 160, 457-467.

Wendt, J. W., \& Hauser, S. (2013). An equivalent soil mass procedure for monitoring soil organic carbon in multiple soil layers. European Journal of Soil Science, 64, 58-65. doi:10.1111/ejss.12002. 
Yoo, K., Amundson, R., Heimsath, A., \& Dietrich, W. (2006). Spatial patterns of soil organic carbon on hillslopes: Integrating geomorphic processes and the biological c cycle. Geoderma, 130, 47-65. doi:10.1016/j.geoderma.2005.01.008.

Zanella, A., Ponge, J.-F., Jabiol, B., Sartori, G., Kolb, E., Gobat, J.-M., Bayon, R.-C. L., Aubert, M., Waal, R. D., Delft, B. V., Vacca, A., Serra, G., Chersich, S., Andreetta, A., Cools, N., Englisch, M., Hager, H., Katzensteiner, K., Brthes, A., Nicola, C. D., Testi, A., Bernier, N., Graefe, U., Juilleret, J., Banas, D., Garlato, A., Obber, S., Galvan, P., Zampedri, R., Frizzera, L., Tomasi, M., Menardi, R., Fontanella, F., Filoso, C., Dibona, R., Bolzonella, C., Pizzeghello, D., Carletti, P., Langohr, R., Cattaneo, D., Nardi, S., Nicolini, G., \& Viola, F. (2017). Humusica 1, article 4: Terrestrial humus systems and formsSpecific terms and diagnostic horizons. Applied Soil Ecology, 122, 56-74. doi:10.1016/j.apsoil.2017.07.005.

Zdruli, P., Lal, R., Cherlet, M., \& Kapur, S. (2017). New World Atlas of Desertification and Issues of Carbon Sequestration, Organic Carbon Stocks, Nutrient Depletion and Implications for Food Security. In Carbon Management, Technologies, and Trends in Mediterranean Ecosystems (pp. 13-25). doi:10.1007/978-3-319-45035-3_2.

Zhao, Z., Wei, X., Wang, X., Ma, T., Huang, L., Gao, H., Fan, J., Li, X., \& Jia, X. (2019). Concentration and mineralization of organic carbon in forest soils along a climatic gradient. Forest Ecology and Management, 432, 246-255. doi:10.1016/j.foreco.2018.09.026. 